\title{
The National Strategy and the Current Situation of Children of the Returned Emigrants in Albania
}

\author{
Denata Hoxha Laro \\ "Aleksander Moisiu' University, Albania \\ Email:denahoxha@gmail.com
}

\section{Doi:10.5901/jesr.2014.v4n3p79}

\section{Abstract}

\begin{abstract}
The albanian education is trying to come out from a total black-out that has accompaigned it through these dificult years of transition. During this process of reformation it has been appeared as a consequence of the change of social aspects, not only in Albania but also in Balcans as well as in Europe the phenomena of the return of emigrants in their native land. This longstanding wound of the albanians is experiencing the boomerang impact regarding the adaption of this target group, no more in the host countries than in the origin one. This adaptation is considered not only in the social and economical aspect, but above all in the educational aspect. Besides the annual changes in our educational system, what can be considered an emergency of the recent years is the adaptation of the children of the returned emigrants with our educational system. This adaptation is written on papers, but virtually is missing in the daily teaching activity in our schools. Now, more than never, at a time when the number of the returned emigrants is increasing everyday, is needed a direct action plan for the adaptation and integration of these children who have evident and numerous difficulties, especially in the linguistic aspect. This article is aiming to analyze the lacks and the needs of this difficult process. Currently this process is entrusted to the teachers without an unified curriculum. The need for the change of this situation is emergent as well as the thorough integration of these returned emigrants.
\end{abstract}

Keywords: the returned emigrants, the educational adaptation, linguistic problems, unified curricula.

\section{The National Strategy}

As a country with a numerous problems and as the origin of millions of emigrants in the years of '90-s, Albania of the millenium 2000 is experiencing the phenomena of boomerang of emigration. Many emigrants are retuning. They are returning to the place of origin with the hope and the need of their own integration, as well as of their children's. These children has been considered as the first generation (the children of emigrants born in the origin country), the second generation (the children of emigrants born in the host countries) and the generation 1.5 (the children of emigrants born in the country of origin but brought in the host countries while they were infants and according to the social logic are nearest with those of second generation (Portes. A, Rivas. A, 2011) While there is a national strategy for protection and reintegration of the children, victims of trafficking, there is no suchlike for the educational and social reintegration for the children of the returned emigrants.

While there are developped the circumstances for the education of the emigrants in the albanian language, (especially in Greece and Italy) and the standard curricula for teaching the albanian language the children of emigrants all over the world, unfortunally there are not developped yet such circumstances in our schools, that day by day are becoming as reception places for the children of the returned emigrants, becoming so as the first step of the reintegration in the albanian social life.

Although the improvement of the legal frame for migration in Albania foresees the inclusion in the Law of the preuniversity Education the provisions that provide the responsibilities of the Albanian state for the teaching of albanian language for the emigrants and their families in accordance with the article 11(2) of the law for the Emigration of the Albanian Citizens Aiming their Emplyment, till this moment there has happenned nothing.

The Albanian government is commited to support the social, cultural and economical integration of the emigrants in the host countries combined it with the keeping and the development of the albanian cultural inheritance (the National Strategy and Action Plan pg. 15). What about the integration of returned albanians in Albania? Certainly, the competent authority for the reintegration of the returned emigrants as well as the emigration issues is the Ministry of Labor, Social Affairs and Equal Opportunities, today as the Ministry of the Social Welfare and Youth). Can this institution realize the 
educational adaptation of the children of emigrants?

While it is said and are taken the measures for the reintegration of the emigrants in the society, it is left out the integration of the children of these emigrants. How is going to happen the educational adaptation of these children who are coming from the scholastic realities different from ours, as well as for those who are returned after a detachment of 23 years in other systems. Uncommonly the MES (the Ministry of Education and Science) isn't one of ministries that will care about the migration policies for the reintegration. The emigration in Albania has been treated mainly in the frame of the measures for combating the trafficking of human beings and the managing of the borders (the National Strategy for Combating the Trafficking of the Human Beings 2001 (the Strategy of Integrated Managing of the Borders 2003). There is an evident lack of the social and educational measures for the reintegration of the emigrant children (the first generation) and of the children of emigrants (the second generation and1.5).

\section{The Actual Situation in Our Schools}

Currently the issue on the reintegration of the returned children is left to the respective teachers and schools considering the basic education too. The schools have taken the instruction to establish specific curricula in case of having such children in their classes. Positively this duty has been given to respective teachers. Especially this curriculum consists on the facilities for linguistic problems. Is in teacher's hands who decide to work within the own teaching lesson or as suplementary lesson out of the schooling time. In any case, with the fact that there is any definite procedure everything is left in the conscience of each teacher who has to do with such children coming from other educational systems.

Thus, beside the lack of a concrete curriculum proposed from central authorities, that would be served as an instruction for the progress of the integration process, there is also the lack of the motivation of the teacher who will have under his responsibility these children. The motivation could be as a supplement of the teaching consignment or a supplemental honorarium.

Among of the children of the first generation there are some who have left the country without entering our educational system, as are some of them who have entered the first 2 years our educational system and then they have left the country. These children have shown a quicker adaption and lesser problematics comparing to the children of the second and 1.5 generation after they have returned and have faced with our educational system. It's clear that these factors, either mitigating or aggravating have a direct relation with the teaching of mother language. The different linguistic problems, such as the written and the spoken issues as well as the definition of intelligibility hamper the academic adaptation and the achievement of the optimal results in all subjects.

Although the children of the three generations have evident differences as regards the academic achievements after they return, their results in both countries (the host and the origin ones) show that the problem is not only at the appropriation of the language (the albanian language or the foreign one). There are children, especially from the first generation who have achieved better results in the host countries than in Albania, these are the cases of the children who have first entered in our educational system and then have left to the reception countries.

The practice and the scholastic experience of these children show also that the children returned from Italy can be adapted easily as regards to the usage of the language comparing to the children returned from Greece, despite the kind of generation they belong to. This is more evident in terms of the spoken language with respective accents of the languages. The agreements for teaching/to teach the mother language in reception countries

\section{The Agreements for Teaching the Mother Language in the Host Countries.}

There are two methods of teaching the mother language to the emigrants students/pupils in the reception countries. (European Commission, 2009):

* The first approach consists on the bilateral agreements between the reception country and the origin country of the major of the emigrants.

* The second approach consist on the certified teaching from the national educational system (Italy, Greece), that is more familiar/regul;ar/normal/usual which is the adaption of the principle/ that the emigrant pupils have the right to learn the mother language.

The teaching of the mother language based on the bilateral agreements is often extracurriculum (European Commission, 2009). This is the case of Greece where the infrastructure is provided from the host country, while the teachers are mainly employed from the origin country and they have a considerable pedagogical autonomy. These teachers are trained in the beginning of every academical year through seminars organized from MES to support the 
specific curricula made notably for diaspora. Furthermore, MES provides the equipment of books for the children of the emigrants in Diaspora. The teaching of the mother language is realized out of the school-time.

Exactly, such simple and mitigating issues on keeping the linguistic and cultural identity in host countries become impassable when these children return and have the need to be integrated or reintegrated into the albanian social reality. In this reality there is not provided an official and well planned programme on teaching the mother language (that hamper the initial adaptation into social community) and the texts haven't been offered free of charge, what has provoked the revolt of the parents, especially for the cases with financial difficulties, (because they have received the texts of the obligatory education free of charge in the host countries).

Concerning the teaching of the mother language provided from the national educational system, Italy has trusted this part to the schools or locak authorities. (European Commission, 2009). While Greece has set a minimum of conditions in order that the teaching of the mother language can be provided (European Commission, 2009):

* 4 hours extra-curricula per week

* The requirement for learning of the mother language from at least 7 pupils.

* The available profesionist teachers

* The teaching is realized out of the schooling-time

Currently the teachings of the mother language in Greece is realized according to the first method, the bilateral agreement where the host country offers the infrastructure and the origin country offers the teachers, the curricula and the texts.

Beside the opportunities to keep the linguistic and cultural identity in the host countries there is provided the teaching of the language of the host countries to the children of the emigrants ( mainly from the first generation) with supplemental teachers through supplemental hours, (the case of Italy). The children of emigrants have the right to approach this teacher whenever they face with linguistic difficulties.

\section{Conclusions}

What happens when these children return to their origin country? Can be overfulfilled all the difficulties within the schooltime of the day while the other part of curriculum continue to be realized normally? Can the teacher manage alone the situation to provide as differential as co-operative teachings within 45 minutes hour? Can this teacher cover also within this time the part of counselling for these children?

At this point arises another issue that has a close relation with the social integration of these children; the importance of the presence of the psychologist of the school. Although every school in the Republic of Albania has included officially the psychologist in the staff structure the presence of this specialist in supporting these cases is almost inexistent . The children don't have any idea about the existence of the psychologist in the school, whiles the role of the psychologist is crucial in facilitating the integration of these children among of their coevals through counseling for any problem or uncertainty during the school-time.

Currently the adaptation of these children in the host countries is easier (Italy presents a good example for its educational system where are foreseen facilities for the integration of such cases of children) than in their origin countries.

Although at the beginning and in the end of each academic year the regional Educational Directories collect the data about the number of the returned children; the number of those with the linguistic problems; the programmes of psychologists in working individually with these children, still the results remain such only on papers.

All these data collected have never resulted on necessity of compiling special curricula for these children; there have never resulted on necessity of planning extra hours and of including specialized teachers that will support the educational integration of these children, that in most of cases are linguistic problems and sometimes are problems of social integration of these children among of their coevals.

The main problem that has been identified in in schools is toward the concrete action and the adaptation of the returned children. It's the responsability of the school to identify the problems of these children; to compile the teachings programmes and the individual work plans for special pupils; to support on overcoming the affective problems caused from the change of the living and schooling environment (at this point is so important to include the psychologists); to help on overcoming the linguistic problems (at this point is important the inclusion of another teacher who will assist and help the main teacher in class).

In this regard, although the strategy for the reintegration of Albanian returnees 2010-2015 gives some main focus frames, again reintegration education of emigrant children is left somewhat in the shade. More priority is given to social 
integration and employment of first generation emigrants than education and social integration of the second generation. The Instructions from the MES consist on fixing these problems from the schools and their reporting at the respective Regional Educational Directories. .In terms of documentation, everything is reported. But, in view of the current state of reintegration on their teaching, not everything is as simple as it is reflected through reports.

\section{References}

Law no. 9668 date 18.12 .2006 for "The emigration of the Albanian citizens' with the reason of employment"

Portes. A, Rivas. A, The Adaption of Migrant Children, vol. 21, nr. 1, 2011

The Albanian Strategy against trafficking of human beings, 2001

The National Strategy "The reintegration of the Albanian citizens returned in country"

The National Strategy Against the Trafficking of the Human Beings 2008-2010

The National Strategy against trafficking and for the protection of children, victims of trafficking,

The National Strategy for Migration and National Action Plan for Migration, 2005

The National Strategy for the Children 2005-2010,

The National strategy for the Children 2010-2015,

The Sectional Strategy of the Employment and Professional Forming 2007-2012,

The Sectional Strategy of the Social Protection 2007-2013,

The Strategy for the reintegration of the returned Albanian citizens,

UNDP, Human Development Report 2009 